\title{
Impact of Traffic Congestion on Spatial Access to Healthcare Services in Nairobi: an ecological study
}

Mutono Nyamai ( $\square$ mutono.nyamai@wsu.edu )

University of Nairobi https://orcid.org/0000-0002-7378-0007

Jim A. Wright

University of Southampton

Mumbua Mutunga

University of Nairobi

Henry Mutembei

University of Nairobi

SM Thumbi

Washington State University

\section{Research Article}

Keywords: Traffic congestion, healthcare accessibility, universal healthcare access, Sub-Saharan Africa, catchment model

Posted Date: October 1st, 2021

DOI: https://doi.org/10.21203/rs.3.rs-948362/v1

License: (c) (i) This work is licensed under a Creative Commons Attribution 4.0 International License.

Read Full License 


\section{Abstract \\ Background}

Geographic accessibility is an important determinant of healthcare utilisation and is critical for achievement of universal health coverage. Despite the high disease burden and severe traffic congestion in many African cities, few studies have assessed how traffic congestion impacts geographical access to healthcare facilities and to health professionals in these settings.

\section{Methods}

Using data on health facilities obtained from the Ministry of Health in Kenya, we mapped 944 primary, 94 secondary and four tertiary healthcare facilities in Nairobi County. We then used traffic probe data to identify areas within a 15-, 30- and 45-minute drive from each health facility during peak and off-peak hours and calculated the proportion of the population with access to healthcare in the County. We employed a 2-step floating catchment area model to calculate the ratio of healthcare and healthcare professionals to population during these times.

\section{Results}

During peak hours, $<70 \%$ of Nairobi's 4.1 million population was within a 30-minute drive from a health facility. This increased to $>75 \%$ during off-peak hours. In 45 minutes, the majority of the population had an accessibility index of one health facility accessible to more than 100 people $(<0.01)$ for primary health care facilities while secondary and tertiary health facilities had a ratio of one health facility for more than 10,000 people $(<0.0001)$ and at least two health facilities per 100,000 people $(>0.00002)$ respectively. Of people with access to health facilities, a sub-optimal ratio of $<2.3$ healthcare professionals per 1000 people was observed in facilities offering primary and secondary healthcare during peak and off-peak hours.

\section{Conclusion}

These findings can guide urban planners and policymakers in improving access to healthcare facilities to optimise coverage during peak and off-peak traffic times. Similarly, growing availability of traffic probe data in African cities should enable similar analysis in other countries.

\section{Background}

An estimated 3.6 million deaths in low- and middle-income countries (LMICs) are associated with nonutilisation of healthcare (1). Timely healthcare access encompassing physical access to quality care, 
acceptability and financial access remains low in many developing economies despite its potential to substantially reduce mortality $(2,3)$.

Health is one of the measures of quality of life, and access to health facilities and skilled workforce in facilities has been prioritised by the United Nations through the Sustainable Development Goals. Goal 3 addresses better access to healthcare and the healthcare workforce with Target 3.8 seeking to achieve universal health coverage (UHC) for all by 2030, while Target 3.c aims to recruit, train, and retain the healthcare workforce in developing countries (4). Population access to these resources has been evaluated using geographical accessibility $(3,5)$.

Geographical accessibility through distance or travel time has been reported as a significant barrier to effective treatment $(6,7)$. Similarly, optimal placement of health facilities has been advocated, which minimise travel distance to health facilities while maximising population coverage $(8,9)$. Research focusing on LMICs has used cost surfaces (for example, the World Health Organisation's (WHO) Access Mod software) and the two-step floating catchment area (2SFCA) method to measure geographical access $(3,7,10)$. However, cost surfaces are less well suited for quantifying patient travel and thereby $\mathrm{UHC}$ complexities in cities experiencing congestion as they expand. On the other hand, the 2SFCA method calculates geographical accessibility of healthcare services through use of the gravity model to analyse the ratio of healthcare supply and population demand, while often incorporating patient mode of transport and road networks, and accounting for the population that has more than one health facility in its proximity $(10,11)$. However, there is limited research on the use of this method to assess the effect of traffic on the proportion of population with access to a health facility and the healthcare workforce, particularly in cities in LMICs which are characterised by rapid urbanisation and poor road infrastructure (12).

Studies of peak and off-peak travel time to health facilities in Africa have primarily used methods that employ road networks $(3,13)$. However, these studies focus on emergency care without incorporating $\mathrm{UHC}$ and the ratio of population to healthcare workforce. Additionally, these studies consider traffic conditions for broad categories of road types, without including disaggregated traffic data. We investigated geographical access to healthcare facilities and professionals in an African city using the 2SFCA method while incorporating traffic data to address two research questions: i) How are healthcare facility catchment areas affected by traffic congestion? ii) How does traffic congestion influence the distribution of healthcare professionals to population across healthcare facilities?

\section{Methods}

\section{Study area}

This study was conducted in Nairobi County, the most populous city in Kenya. The 2019 census data estimated Nairobi's population at 4.4 million with a population density of 6,247 per $\mathrm{km}^{2}$ (14). 
In Kenya, health facilities are divided into four tiers based on the level of care offered. Tier I comprises community health services, providing mainly community health volunteer visits and health promotion messages. Tier II comprises the lowest level of health facilities that offer primary healthcare services (dispensaries, clinics, health centres and maternity centres). Tier III comprises sub-County hospitals, medium-sized and large private hospitals, County hospitals and large private teaching hospitals, which offer secondary healthcare services while, Tier IV are national referral hospitals that offer tertiary healthcare services (Figure 1)(15). Tiers I and II focus on health promotion and prevention, while Tiers III and IV prioritise curative services (15).

In 2020, Nairobi County had 1,042 health facilities registered under the Ministry of Health (16), yielding a ratio of 23.7 health facilities per 100,000 people. The majority (91\%) of these facilities offered primary healthcare services while $\sim 9 \%$ and $\sim 1 \%$ offered secondary and tertiary healthcare services respectively. In addition, $74 \%$ of these health facilities were privately owned.

Kenya is one of two African countries for which the Environmental Systems Research Institute (ESRI) have online historical traffic data available to support drive-time calculations (17). Approximately $88 \%$ of motorised public transport trips by urban residents in Kenya are in a matatu (a type of minibus) (18).

\section{Facility geocodes}

In September 2020, we downloaded a list of health facilities registered in Nairobi from the Ministry of Health-Kenya Master Health Facility List (16). Public health facility coordinates were extracted from a previous study (19). Geocodes of private health facilities were obtained by use of street level precision of Google Earth Pro's geocoding service (version 7.3) which has low positional error (20).

\section{Population data}

We used the 2019 population data from WorldPop which are calculated using official country census data, administrative boundary maps and ancillary geospatial data sets of road networks, hospital facilities, satellite imagery and building or settlement maps (21). Aggregate population counts from the 2009 census for sub-locations (areas with a mean population of 5,400) were projected to 2019 and redistributed within each boundary onto constituent 100 by 100 metres resolution grid cells. Using a random forest dasymetric mapping algorithm, the population in every grid cell was predicted from covariates such as distance to urban areas, unvegetated areas, settlement built-up areas, water bodies, roads and night-time lights, among others (22).

\section{Health facility catchment area}

To estimate the catchment areas for healthcare facilities, we used ESRI routing services which collect historical traffic data from probes, which are global positioning system (GPS) enabled devices embedded in vehicles or carried by passengers for example cell phones (23). The probes are able to relay their location in real time at frequent refresh rates. This system calculates distance- and time-based catchment areas, accounting for mode of transport, road networks and traffic regulations (24). To analyse the impact of traffic congestion on motorised access to healthcare services relative to the catchment areas, 
we selected three travel cut-off times (15, 30 and 45 minutes) and compared travel times during randomly selected peak- and off-peak traffic hours. Peak hours included Monday 8am and Wednesday 6pm, while off-peak hours included Sunday 8 am and Saturday $6 \mathrm{pm}$.

We computed the ratio of health facilities to the population using a 2SFCA method adapted from Ahmed et al (25). In this method, the catchment areas for each health facility within a given threshold are calculated and the population within the catchment area tabulated. For population falling within the catchment area of more than one health facility per category, the ratios are summed up to assess the accessibility index for each population.

(i) Ratio (R) of health facilities (F) to population (P)

The population $(\mathrm{P})$ that was within the travel time $\left(t t_{0}\right)$ of each health facility $(\mathrm{F})$ was calculated and the ratio of health facilities to the population $R_{f}$ was computed using:

$$
R_{f}=\frac{F}{\sum_{f \in t_{f \leq t_{0}}} P_{f}}
$$

We then calculated the population accessibility index by computing the ratio of health facilities to population in 100 by 100 metre grid cells. For populations with access to $>1$ healthcare facility within the travel threshold of each point representing the population, the ratio of healthcare facility to population for each level of facility was summed up. Population that was not within the catchment area of at least one health facility per category was defined as underserved. We used the Z-test to compare facility-level populations accessing health facilities during peak and off-peak hours.

\section{Ratio of healthcare professionals to population}

We used average staffing levels for healthcare professionals across healthcare categories as reported in the Kenya Service Provision Assessment (KSPA) Survey of 2010 (Table 1) (27). The KSPA survey included 703 facilities which were randomly selected from the Master Health Facility List. Data on staffing were collected and averaged according to the level of care.

Table 1

The average number of healthcare professionals per facility in Kenya in 2011, by healthcare category

\begin{tabular}{|llll|}
\hline Health facility category & Primary & Secondary & Tertiary \\
\hline Nurses/midwives & 8 & 13 & 288 \\
\hline Clinical officers & 3 & 4 & 30 \\
\hline Doctors & - & 2 & 10 \\
\hline Total & 11 & 19 & 328 \\
\hline Source: National Coordinating Agency for Population and Development et al, 2017 (27) \\
\hline
\end{tabular}


(ii) Ratio (R) of healthcare professionals (HP) to population (P)

The population $(\mathrm{P})$ that was within the travel time $\left(t t_{0}\right)$ of healthcare professionals $(\mathrm{HP})$ in each facility ( $f$ ) was calculated and the ratio of healthcare professionals to the population $R_{h p}$ was computed using:

$$
R_{h p}=\frac{H P}{\sum_{f \in t t_{f \leq t_{0}}} P_{h p}}
$$

We then calculated the population accessibility index by computing the ratio of healthcare professionals to population in 100 by 100 metre grid cells. For populations with access to $>1$ health facility within the travel threshold of each point representing the population, the ratio of healthcare professionals to population for each facility was summed. Populations outside facility catchment areas were considered inaccessible to healthcare professionals. We used the WHO recommendations of 2.3 healthcare professionals (doctors, clinical officers, nurses, midwives) per 1000 people to classify access as suboptimal (<2.3:1000) or optimal (>2.3:1000) (28). To cater for edge effects, we applied a 2.5-kilometre buffer from administrative boundaries, recalculated the healthcare professional to population ratio and the accessibility index, and used the new values to classify access as either optimal or sub-optimal. The analysis and visualisation was conducted using R statistical software version 4.0.4 (29).

\section{Results}

The proportion of the population within the catchment areas of each level of healthcare that could access the healthcare facilities within $\leq 15,30$ and 45 minutes during off-peak hours was significantly reduced during peak traffic times. This was observed for primary, secondary, and tertiary health facilities, except for secondary health facilities which were accessible to the whole population during peak and off-peak hours (Table 2). During peak hours, $45 \%, 20 \%$ and $17 \%$ of the population could access primary, secondary, and tertiary health facilities respectively, within 15 minutes. Access increased among these facilities by $3 \%, 23 \%$ and $13 \%(p<0.001)$ respectively during off-peak hours. At 30 minutes, $>50 \%$ of the population was able to access the three levels of health facilities, with the greatest proportion having access to primary healthcare during peak $(68 \%)$ and off-peak $(75 \%)$ hours. Tertiary healthcare had the lowest population access (55\%) at 30 minutes during peak hours. 
Table 2

Distribution of Nairobi's 4.1 million residents within 15, 30 and 45 minutes' drive-time to different levels of health facilities during peak and off-peak traffic hours

\begin{tabular}{|c|c|c|c|c|}
\hline \multirow[t]{2}{*}{ Healthcare level } & \multirow[t]{2}{*}{ Time (min) } & \multicolumn{2}{|c|}{ Population in millions (\%) } & \multirow[t]{2}{*}{$p$-value } \\
\hline & & Peak hours & Off-peak hours & \\
\hline \multirow[t]{3}{*}{ Primary } & $\leq 15 \min$ & $1.8(45 \%)$ & $2.0(48 \%)$ & $<0.001$ \\
\hline & $\leq 30 \min$ & $2.8(68 \%)$ & $3.1(75 \%)$ & $<0.001$ \\
\hline & $\leq 45 \mathrm{~min}$ & $3.9(95 \%)$ & $4.0(97 \%)$ & $<0.001$ \\
\hline \multirow[t]{3}{*}{ Secondary } & $\leq 15 \min$ & $0.8(20 \%)$ & $1.8(43 \%)$ & $<0.001$ \\
\hline & $\leq 30 \min$ & $2.5(62 \%)$ & $2.9(71 \%)$ & $<0.001$ \\
\hline & $\leq 45 \min$ & $4.1(100 \%)$ & $4.1(100 \%)$ & 1 \\
\hline \multirow[t]{3}{*}{ Tertiary } & $\leq 15 \min$ & $0.7(17 \%)$ & $1.3(30 \%)$ & $<0.001$ \\
\hline & $\leq 30 \min$ & $2.3(55 \%)$ & $2.9(71 \%)$ & $<0.001$ \\
\hline & $\leq 45 \min$ & $3.6(86 \%)$ & $3.7(91 \%)$ & $<0.001$ \\
\hline
\end{tabular}

\section{Geographical access to healthcare}

The spatial coverage of Tier II health facilities during peak and off-peak hours was predominantly in the central region of Nairobi County, with the peripheries underserved both during the peak and off-peak traffic times. In 15 minutes, only $2 \%$ and $8 \%$ of the population able to access health facilities had an accessibility index of $\geq 0.01$ during peak and off-peak traffic times respectively. This meant that at least one health facility per 100 people was within the catchment area. The rest had an accessibility index of $<0.01$, where more than 100 people were able to access one health facility within the given threshold. In 30 minutes, the proportion of the population with an accessibility index of at least one heath facility per 100 population increased to $18 \%$ and $16 \%$ during peak and off-peak traffic times respectively. In 45 minutes, two thirds of the population, $67 \%$ during peak time and $69 \%$ during off-peak hours had an accessibility index of one health facility offering primary health care to more than 100 people $(<0.01)$ 
within the given threshold. The rest had at least one health facility per 100 people. On the other hand, less than $1 \%$ of the population, predominantly in the southwestern region, had a relatively higher accessibility index of at least two health facilities per 100 people within the three cut-off times, during peak and offpeak traffic periods. (Figure 3).

In secondary health care facilities, the coverage was mainly in the central region, with the peripheries having a relatively better coverage, when compared to primary health care facilities. In 15 minutes, the accessibility index for $99 \%$ of the population was lower than primary health care where more than 10,000 people had access to one hospital $(<0.0001)$ both during peak and off-peak traffic times. In 30 minutes, majority of the population, $97 \%$ during peak and $96 \%$ during off peak traffic times had an accessibility index of at least five facilities per 10,000 people. In 45 minutes, $75 \%$ and $78 \%$ of the population had an accessibility index of $<0.0001$ where one hospital was primarily within access to more than 10,000 people during peak and off-peak traffic times respectively. Less than $1 \%$ of the population had a relatively better accessibility index of at least two facilities accessible to 10,000 individuals. The peripheries were underserved in accessing the health facilities in less than 30 minutes during peak and off-peak traffic scenarios as they had no access to a facility (Figure 4).

Similar to facilities offering primary and secondary health care, tertiary health facilities were mostly accessible to the population in the central region. The accessibility index of the number of health facilities to population ranged from 1 to 3 health facilities accessible to 100,000 people. In 45 minutes, $2 \%$ and $3 \%$ of the population had an accessibility index of more than 100,000 people to one facility whereas $80 \%$ and $86 \%$ of the population had a relatively better accessibility index of at least two facilities per 100,000 people during peak and off-peak traffic times respectively. The eastern region and the peripheries were predominantly underserved with no Tier IV health facility within fifteen, thirty and fortyfive minutes' drive time during peak and off-peak traffic scenarios (Figure 5).

\section{Ratio of the healthcare professionals to the population}

All the population that was able to access health facilities offering tertiary care within 15 and 30 minutes had an optimal accessibility ratio of healthcare professionals which was above the recommended ratio of 2.3 per 1000 people during peak and off-peak traffic scenarios. On the other hand, secondary health care facilities had the highest proportion of population that had a sub-optimal ratio of below 2.3 healthcare professionals per 1000 people. In the proportion that was able to access secondary health care facilities in less than thirty minutes, more than $60 \%$ had a sub-optimal ratio of healthcare professionals during peak and off-peak traffic times. On the other hand, excluding population within 2.5 kilometre of the study area boundary significantly reduced the population with a sub-optimal ratio of healthcare professionals in both primary and secondary health facilities (Table 3). 
Table 3

Population with a sub-optimal ratio of less than 2.3 healthcare professionals per 1000 within 15,30 and 45 minutes of primary, secondary, and tertiary healthcare in Nairobi, during peak and off-peak traffic

times

\begin{tabular}{|c|c|c|c|c|c|c|c|}
\hline \multirow{3}{*}{$\begin{array}{l}\text { Healthcare } \\
\text { level }\end{array}$} & \multirow[t]{3}{*}{ Time } & \multicolumn{6}{|c|}{ Population in millions (\%) } \\
\hline & & \multicolumn{3}{|c|}{$\begin{array}{l}<2.3 \text { healthcare workers per } 1000 \\
\text { population (no buffer) }\end{array}$} & \multicolumn{3}{|c|}{$\begin{array}{l}<2.3 \text { healthcare workers per } 1000 \\
\text { population }(2.5 \mathrm{~km} \text { buffer included) }\end{array}$} \\
\hline & & Peak & Off-peak & $p$-value & Peak & Off-peak & $p$-value \\
\hline \multirow[t]{3}{*}{ Primary } & $\begin{array}{l}<15 \\
\min \end{array}$ & $0.7(16 \%)$ & $1.2(28 \%)$ & $<0.001$ & $0.5(11 \%)$ & $0.8(19 \%)$ & $<0.001$ \\
\hline & $\begin{array}{l}<30 \\
\min \end{array}$ & $1.5(37 \%)$ & $1.7(42 \%)$ & $<0.001$ & $1.0(25 \%)$ & $1.2(29 \%)$ & $<0.001$ \\
\hline & $\begin{array}{l}<45 \\
\min \end{array}$ & $1.9(47 \%)$ & $1.9(47 \%)$ & 1 & $1.3(32 \%)$ & $1.3(32 \%)$ & 1 \\
\hline \multirow[t]{3}{*}{ Secondary } & $\begin{array}{l}<15 \\
\min \end{array}$ & $0.8(19 \%)$ & $1.8(44 \%)$ & $<0.001$ & $0.7(17 \%)$ & $1.6(39 \%)$ & $<0.001$ \\
\hline & $\begin{array}{l}<30 \\
\min \end{array}$ & $2.5(62 \%)$ & $2.9(71 \%)$ & $<0.001$ & $2.3(55 \%)$ & $2.6(63 \%)$ & $<0.001$ \\
\hline & $\begin{array}{l}<45 \\
\min \end{array}$ & $3.2(79 \%)$ & $3.2(79 \%)$ & 1 & $2.9(70 \%)$ & $2.9(70 \%)$ & 1 \\
\hline \multirow[t]{3}{*}{ Tertiary } & $\begin{array}{l}<15 \\
\min \end{array}$ & 0 & 0 & 1 & 0 & 0 & 1 \\
\hline & $\begin{array}{l}<30 \\
\min \end{array}$ & 0 & 0 & 1 & 0 & 0 & 1 \\
\hline & $\begin{array}{l}<45 \\
\min \end{array}$ & $0.3(8 \%)$ & $1.3(31 \%)$ & $<0.001$ & $0.3(6 \%)$ & $1.0(24 \%)$ & $<0.001$ \\
\hline
\end{tabular}

Spatial visualisation of accessibility of healthcare professionals in Nairobi County varied, depending on journey time threshold, traffic conditions, and level of healthcare. Facilities offering tertiary healthcare were able to adequately cover the central and northern region of Nairobi, while primary health care facilities covered the western and eastern region. Secondary health facilities had a predominantly suboptimal accessibility ratio in the central region (Figure 6). In less than 30 minutes, the population residing in the peripheries was mainly not able to access healthcare professionals, both during peak and off-peak traffic times.

\section{Discussion}

In this study, we use the 2SFCA method to calculate the accessibility of the population to healthcare facilities and professionals, comparing peak and off-peak traffic times while accounting for edge effects. 
We report that traffic congestion plays a significant role on the proportion of population able to access the different levels of healthcare with more than a third of the population not able to access health facilities within 30 minutes' drive time. Similarly, $4 \%, 16 \%$ and $11 \%$ of the population can access facilities offering primary, secondary, and tertiary healthcare services during off-peak traffic times but experience poorer geographic access during peak traffic times. Patterns of inequality are observed where the peripheries are predominantly underserved by inaccessible health facilities and healthcare professionals during periods of traffic congestion. With the population able to access health facilities, a sub-optimal ratio of less than 2.3 healthcare professionals per 1000 people is generally observed in facilities offering primary and secondary healthcare, with edge effects playing a significant role in the ratio.

These results are similar to those of two studies conducted in Dhaka and Nairobi which reported that traffic congestion had a significant impact on the physical accessibility of health facilities that offer emergency health care, with low accessibility indices of these health facilities observed in congested areas $(13,25)$. Transportation barriers to accessing amenities have been associated with delayed access in essential health services (30). A study in KwaZulu-Natal reported that the time spent by patients in commuting and at the health facility per month increased the likelihood of financial distress in a patient (31). This may be explained by the time spent away from the workplace, affecting the patients' income. To increase adherence to healthcare visits, one of the strategies would be to use traffic variation on physical access of health facilities to plan on the optimal placement of future healthcare facilities offering primary and curative services.

One of the primary goals of achieving universal coverage of essential health services for all by 2030 is to increase access to curative healthcare services and adequate workforce (32). However, results from our study showed sub-optimal access to healthcare professionals. Additionally, the WHO has reported suboptimal availability of these professionals in developing countries, particularly in sub-Saharan Africa (28). This shortage may be explained by the multiple jobholding of healthcare professionals in developing countries who are mostly employed by government-owned health facilities, but also consult in privately owned hospitals, and also the emigration of healthcare professionals to developed countries $(33,34)$.

A significant change in the ratio of healthcare professionals to population was observed during the implementation of edge effects, with the central regions enjoying relatively better access to health facilities and ratio of population to healthcare professionals. This was in contrast to results from a study in France that observed only minor variation in accessibility of healthcare when edge effects were considered (35). This difference in study findings may be explained by the structure of the city and the healthcare utilisation of the population in the periphery in developing regions. Many LMICs have expanded rapidly outwards from a formally planned core, often with limited regulatory oversight or planning (36). This structure has influenced the peripheries as these areas are forgotten during planning and development of basic social services(37). One of the coping mechanisms of the peripheries has been utilisation of healthcare services from neighbouring areas which are relatively closer. This was observed in Ghana where residents in the peripheries utilised healthcare services from the neighbouring areas (38). 
Peripheries should be included when planning the development of cities to ensure there is adequate service provided for all residents in the administrative boundary.

Similar to healthcare, a study conducted in Nairobi, a rapidly urbanising city, reported that more than three quarters of the population in Nairobi was not able to access jobs in the city during peak time, with the population residing in peripheries being highly disadvantaged (39). These findings thus add to evidence that traffic variation plays a significant role in accessibility of services. The 2SFCA method should be used in the optimal placement of public amenities and services in congested cities. Specifically, this may be augmented with use of probe traffic data which is available from different commercial sources and with increasing global coverage in rapidly urbanising LMIC cities (40).

One major assumption of this study, which has also been evidenced in previous studies, was the use of the 2SFCA as a key measure of spatial accessibility to healthcare services and professionals using equal accessibility of the population within the catchment area regardless of time taken to the health facility (41). Enhanced Two Step Floating Catchment Area (E2SFCA) and three-step Floating Catchment Area (3SFCA) methods have been proposed to account for this weakness, though a standard distance or timedecaying method is not yet proposed $(42,43)$. Another shortfall of the 2SFCA method was the unavailability of a standard metric on the minimum time that one ought to travel while seeking healthcare services and the ratio of healthcare professionals to population, making it difficult to compare study findings from different countries or populations (44). UHC, which seeks to ensure that every person should have equitable access to quality healthcare services which are available when needed, should propose a recommended time that should be taken in seeking the different levels of healthcare services. Similarly, a recommended ratio of the cadre of healthcare professionals to population should be proposed, while keeping in mind that the urban population is not willing to travel longer distances to seek healthcare as compared to the rural population (42). Another assumption made in the study was the use of an average number of healthcare professionals to represent all the health facilities in a given service tier. The WHO has designed a registry of healthcare professionals with the aim of helping countries track their health workforce per facility (45). However, this data for Kenya was not readily available to allow comprehensive calculation of the accessibility index of the population to the healthcare workers (46). A future study should assess the number of healthcare professionals per health facility and determine the precise ratio between healthcare professionals and the population.

Routing services such as those provided by ESRI currently use historic traffic data to estimate mean journey times at specific times of week and day. From a health services planning perspective, unpredictability in travel times may give rise to missed appointments and healthcare system costs(47). Routing services that estimate the variance in travel times alongside the mean could thus support future studies of UHC in congested cities (30).

\section{Conclusion}


We argue that traffic congestion should be incorporated by urban planners and policy makers while planning for healthcare and other services in rapidly urbanising cities. Travel time taken to access a health facility has implications on non-utilisation of healthcare and delayed healthcare. Similarly, ratio of healthcare workforce to the population should be incorporated in planning for healthcare to optimise coverage during peak and off-peak traffic times.

\section{Abbreviations}

\section{SFCA}

Two step floating catchment area

\section{ESRI}

Environmental Systems Research Institute

\section{GADM}

Global Administrative Area Database

KSPA

Kenya Service Provision Assessment

\section{LMIC}

Low and Middle Income Countries

PHC

Primary Healthcare

SHC

Secondary Healthcare

THC

Tertiary Healthcare

UHC

Universal Health Coverage

\section{Declarations}

Ethics approval and consent to participate: Not applicable

Consent for publication: Not applicable

Availability of data and materials: The population data was extracted from WorldPop while the traffic data from HERE was utilised through the network routing services from Environmental Systems Research Institute (ESRI). The list of health facilities in Nairobi County were collected from the Kenya Master Health Facility list and the coordinated for public health facilities were collected from a previous study by Njeru et al. The private health facilities were geocoded, and the data is available from this repository: 10.17605/OSF.IO/RJYBC.

Competing interests: None 
Funding: The network routing analysis of the catchment of health facilities was funded by Africa Geoportal.

Author's contributions: NM, SMT and JAW conceptualised the study; NM and MM analysed the data; NM wrote the first draft of the manuscript; SMT, JAW and HM offered mentorship and wrote the manuscript, all the authors read and approved the final manuscript.

Acknowledgements: The authors would like to acknowledge Pauline Okeyo and Kevin Mungai of Africa Geoportal for technical support and Harriet Oboge and Sylvia Omulo from Paul G. Allen School for Global Health, Washington State University for useful discussions on the manuscript findings.

\section{References}

1. Kruk ME, Gage AD, Joseph NT, Danaei G, García-Saisó S, Salomon JA. Mortality due to low-quality health systems in the universal health coverage era: a systematic analysis of amenable deaths in 137 countries. Lancet. 2018;392(10160):2203-12.

2. Peters DH, Garg A, Bloom G, Walker DG, Brieger WR, Hafizur Rahman M. Poverty and access to health care in developing countries. Ann N Y Acad Sci. 2008;1136:161-71.

3. Ouma PO, Maina J, Thuranira PN, Macharia PM, Alegana VA, English M, et al. Access to emergency hospital care provided by the public sector in sub-Saharan Africa in 2015: a geocoded inventory and spatial analysis. Lancet Glob Heal [Internet]. 2018;6(3):e342-50. Available from: http://dx.doi.org/10.1016/S2214-109X(17)30488-6.

4. United Nations. Sustainable Develoment Goals: 17 Goals to transform our world. 2015.

5. Kapologwe NA, Meara JG, Kengia JT, Sonda Y, Gwajima D, Alidina S, et al. Development and upgrading of public primary healthcare facilities with essential surgical services infrastructure: $A$ strategy towards achieving universal health coverage in Tanzania. BMC Health Serv Res. 2020;20(1):1-14.

6. Al-Taiar A, Jaffar S, Assabri A, Al-Habori M, Azazy A, Al-Gabri A, et al. Who develops severe malaria? Impact of access to healthcare, socio-economic and environmental factors on children in Yemen: $A$ case-control study. Trop Med Int Heal. 2008;13(6):762-70.

7. Kuupiel D, Adu KM, Bawontuo V, Tabong PTN, Adogboba DA, Mashamba-Thompson TP. Geographical access to point-of-care testing for hypertensive disorders of pregnancy as an integral part of maternal healthcare in Ghana. BMC Pregnancy Childbirth. 2020;20(1):1-9.

8. Airey T. The impact of road construction on the spatial characteristics of hospital utilization in the Meru district of Kenya. Soc Sci Med. 1992;34(10):1135-46.

9. Toh K, Ben, Millar J, Psychas P, Abuaku B, Ahorlu C, Oppong S, et al. Guiding placement of health facilities using malaria criteria and interactive tool. Res Sq. 2021;1-17.

10. McGrail MR. Spatial accessibility of primary health care utilising the two step floating catchment area method: An assessment of recent improvements. Int J Health Geogr. 2012;11:1-12. 
11. Luo W, Qi Y. An enhanced two-step floating catchment area (E2SFCA) method for measuring spatial accessibility to primary care physicians. Heal Place. 2009.

12. Jain V, Sharma A, Subramanian L. Road traffic congestion in the developing world. Proc 2nd ACM Symp Comput Dev DEV 2012. 2012.

13. Fraser MS, Wachira BW, Flaxman AD, Lee AY, Duber HC. Impact of traffic, poverty and facility ownership on travel time to emergency care in Nairobi, Kenya. African J Emerg Med [Internet]. 2020;10(1):40-5. Available from: https://doi.org/10.1016/j.afjem.2019.12.003.

14. Kenya National Bureau of Statistics. 2019 Kenya Population and Housing Census Volume 1: Population by County and Sub-County [Internet]. Vol. I, 2019 Kenya Population and Housing Census. 2019. 49 p. Available from: https://www.knbs.or.ke/?wpdmpro=2019-kenya-population-and-housingcensus-volume-i-population-by-county-and-sub-county.

15. Kenya Ministry of Health. Kenya Health Policy 2014-2030. 2014.

16. Kenya Ministry of Health. Kenya Master Health Facility List [Internet]. 2020 [cited 2020 Jul 14]. Available from: http://kmhfl.health.go.ke/\#/home.

17. Esri. Network analysis coverage [Internet]. 2020 [cited 2020 Dec 5]. Available from: https://developers.arcgis.com/rest/network/api-reference/network-coverage.htm.

18. Salon D, Gulyani S. Commuting in Urban Kenya: Unpacking travel demand in large and small Kenyan cities. Sustain. 2019;11(14):1-22.

19. Maina J, Ouma PO, Macharia PM, Alegana VA, Mitto B, Fall IS, et al. A spatial database of health facilities managed by the public health sector in sub Saharan Africa. Sci Data. 2019;6(1):1-8.

20. Ribeiro Al, Olhero A, Teixeira H, Magalhães A, Pina MF. Tools for address georeferencing - Limitations and opportunities every public health professional should be aware of. PLoS One. 2014;9(12):1-13.

21. WorldPop. Open Spatial Demographic Data and Research. 2020.

22. Stevens FR, Gaughan AE, Linard C, Tatem AJ. Disaggregating census data for population mapping using Random forests with remotely-sensed and ancillary data. PLoS One. 2015;10(2):1-22.

23. Zhang Z, Wang Y, Chen P, He Z, Yu G. Probe data-driven travel time forecasting for urban expressways by matching similar spatiotemporal traffic patterns. Transp Res Part C Emerg Technol [Internet]. 2017;85(August):476-93. Available from: http://dx.doi.org/10.1016/j.trc.2017.10.010.

24. Esri. Routing services [Internet]. 2020 [cited 2020 Sep 8]. Available from: https://enterprise.arcgis.com/en/server/latest/publish-services/windows/what-is-a-routingservice.htm.

25. Ahmed S, Adams AM, Islam R, Hasan SM, Panciera R. Impact of traffic variability on geographic accessibility to $24 / 7$ emergency healthcare for the urban poor: A GIS study in Dhaka, Bangladesh. PLoS One. 2019;14(9):1-20.

26. GADM. Database of Global Administrative Areas. 2020.

27. National Coordinating Agency for Population and Development, Ministry of Medical Services, Ministry of Public Health and Sanitation, Kenya National Bureau of Statistics, ICF Macro. Kenya 
Service Provision Assessment Survey 2010 [Internet]. Kenya Service Provision Assessment Survey. 2011. Available from: https://esaro.unfpa.org/sites/default/files/pub-pdf/Kenya Service Provision Assessment Survey 2010.pdf\%0Ahttp://dhsprogram.com/pubs/pdf/SPA17/SPA17.pdf.

28. World Health Organization. Working together for Health. Actual Probl Econ. 2006;(9):3-10.

29. R Core Team. R: A language and environment for statistical computing. Vienna: R Foundation for Statistical Computing; 2020.

30. Syed ST, Gerber BS, Sharp LK. Traveling Towards Disease: Transportation Barriers to Health Care Access. J Community Health. 2013;38(5):976-93.

31. Chimbindi N, Bor J, Newell M-L, Tanser F, Baltussen R, Hontelez J, et al. Time and Money: the true costs of health care utilization for patients receiving 'free' HIV/TB care and treatment in rural KwaZulu-Natal Natsayi. JAIDS J Acquir Immune Defic Syndr [Internet]. 2015 Oct 1;70(2):e52-60. Available from: https://journals.Iww.com/00126334-201510010-00017.

32. United Nations. Sustainable Development Goals: 17 Goals to Transform our world [Internet]. United Nations. 2015 [cited 2018 Jan 2]. Available from: http://www.un.org/sustainabledevelopment/waterand-sanitation/.

33. Baughman RA, Stanley B, Smith KE. Second Job Holding Among Direct Care Workers and Nurses: Implications for COVID-19 Transmission in Long-Term Care. Med Care Res Rev. 2020.

34. Dovlo D. Migration of nurses from Sub-Saharan Africa: A review of issues and challenges. Health Serv Res. 2007;42(3 II):1373-88.

35. Gao F, Kihal W, Meur N, Le, Souris M, Deguen S. Does the edge effect impact on the measure of spatial accessibility to healthcare providers ? Int J Health Geogr [Internet]. 2017;1-16. Available from: https://doi.org/10.1186/s12942-017-0119-3.

36. Kingoriah GK. The causes of Nairobi's city structure. Ekistics. 1983;50(301):246-54.

37. Woltjer J. A Global Review on Peri-Urban Development and planning. J Reg City Plan [Internet]. 2014;25(1):10-1. Available from: http://www.tulane.edu/ sbc2003/pdfdocs/0561.PDF.

38. Dotse-Gborgbortsi W, Dwomoh D, Alegana V, Hill A, Tatem AJ, Wright J. The influence of distance and quality on utilisation of birthing services at health facilities in Eastern Region, Ghana. BMJ Glob Heal. 2020;4:1-11.

39. Nakamura S, Avner P. Spatial distributions of job accessibility, housing rents, and poverty: The case of Nairobi. J Hous Econ [Internet]. 2021;51(December 2020):101743. Available from: https://doi.org/10.1016/j.jhe.2020.101743.

40. Dotse-Gborgbortsi W, Wardrop N, Adewole A, Thomas MLH, Wright J. A cross-sectional ecological analysis of international and sub-national health inequalities in commercial geospatial resource availability. Int J Health Geogr [Internet]. 2018;17(1):1-15. Available from: https://doi.org/10.1186/s12942-018-0134-z.

41. Tao Z, Cheng Y, Zheng Q, Li G. Measuring spatial accessibility to healthcare services with constraint of administrative boundary: A case study of Yanqing District, Beijing, China. Int J Equity Health. 2018;17(1):1-12. 
42. McGrail MR, Humphreys JS. Measuring spatial accessibility to primary care in rural areas: Improving the effectiveness of the two-step floating catchment area method. Appl Geogr [Internet]. 2009;29(4):533-41. Available from: http://dx.doi.org/10.1016/j.apgeog.2008.12.003.

43. Wan N, Zou B, Sternberg T. A three-step floating catchment area method for analyzing spatial access to health services. Int J Geogr Inf Sci. 2012;26(6):1073-89.

44. Langford M, Higgs G, Fry R. Multi-modal two-step floating catchment area analysis of primary health care accessibility. Heal Place [Internet]. 2016;38:70-81. Available from:

http://dx.doi.org/10.1016/j.healthplace.2015.11.007.

45. World Health Organization. Human resources for health information system: Minimum Data Set for Health Workforce Registry. 2015; Available from:

http://www.who.int/hrh/statistics/minimun_data_set.pdf.

46. Wangia E, Kandie C. Policy Brief:Refocusing on quality of care. 2018; Available from: http://www.health.go.ke/wp-content/uploads/2019/01/UHC-QI-Policy-Brief.pdf.

47. Bimpou K, Ferguson NS. Dynamic accessibility: Incorporating day-to-day travel time reliability into accessibility measurement. J Transp Geogr [Internet]. 2020;89(January 2019):102892. Available from: https://doi.org/10.1016/j.jtrangeo.2020.102892.

\section{Figures}

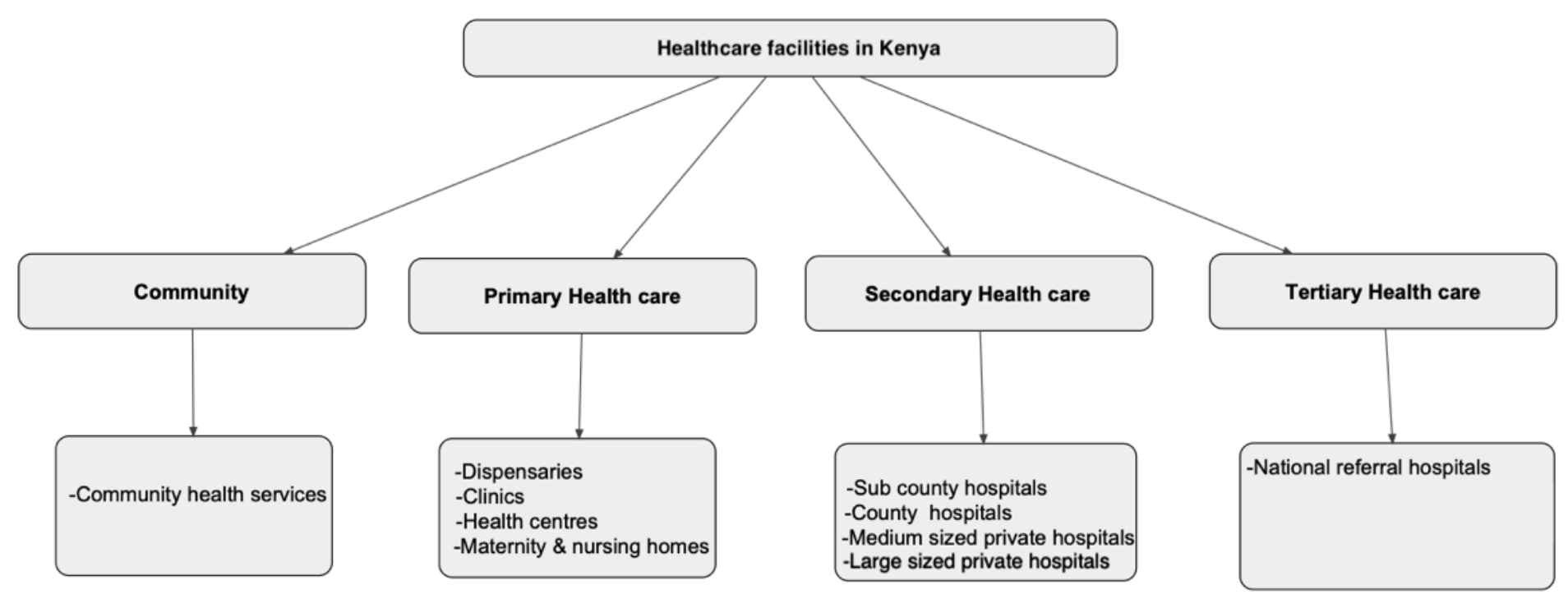

\section{Figure 1}

The four categories of healthcare in Kenya. Source: Kenya Health Policy 2014-2030 (15) 


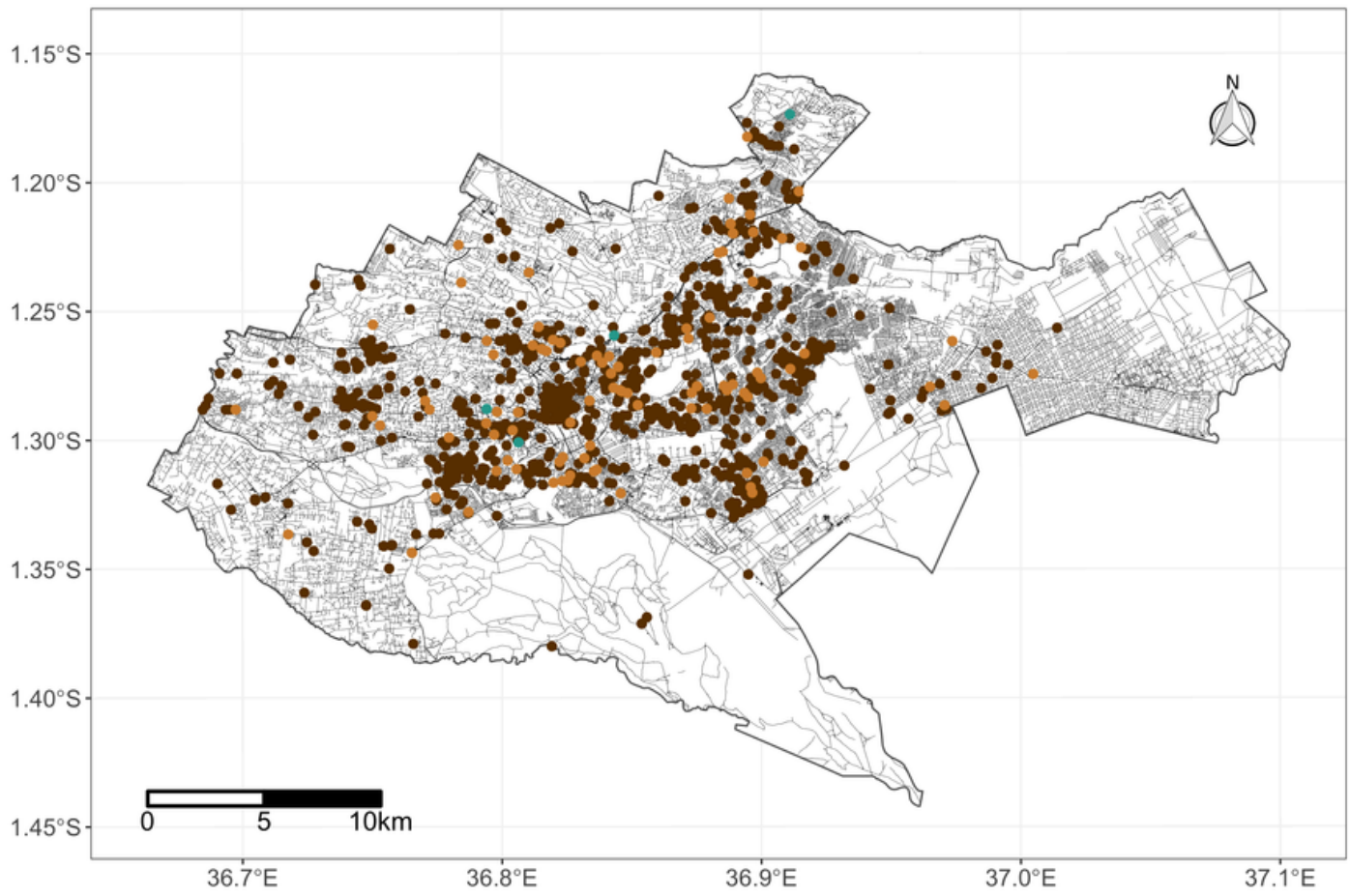

Legend

- Primary Health Care

- Secondary Health Care

- Tertiary Health Care

- Road network

$\square$ Boundary of Nairobi

\section{Figure 2}

Road network coverage and locations of health facilities in Nairobi County, Kenya Source:

OpenStreetMap, Ministry of Health. Shapefile source: GADM (26) 

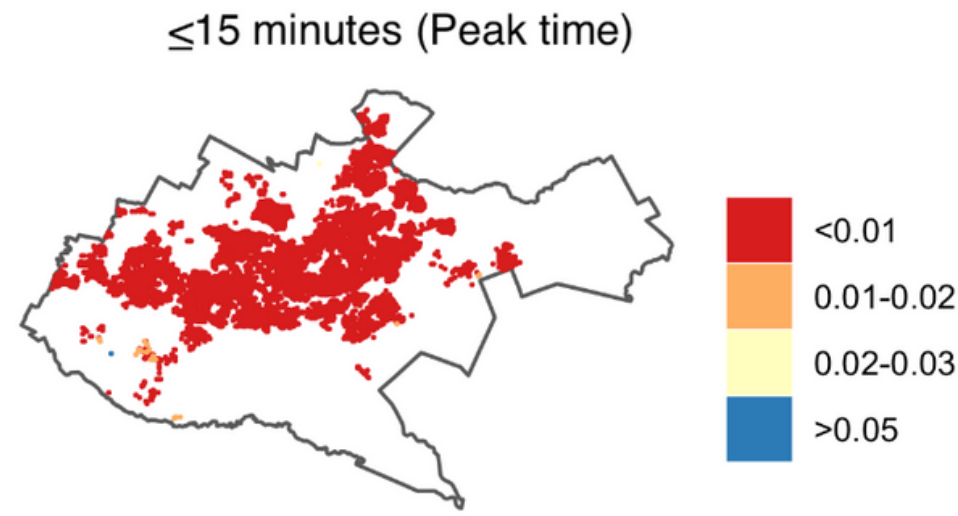

$\leq 15$ minutes (Off-peak time)

$\leq 30$ minutes (Peak time)

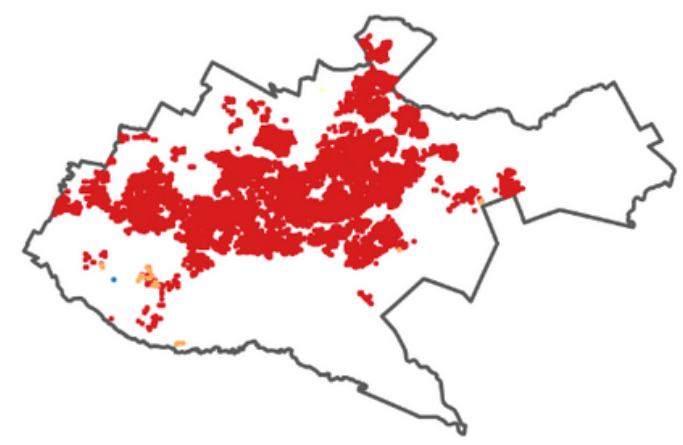

$<0.01$

0.01-0.02

0.02-0.03

$>0.05$

$\leq 30$ minutes (Off peak time)
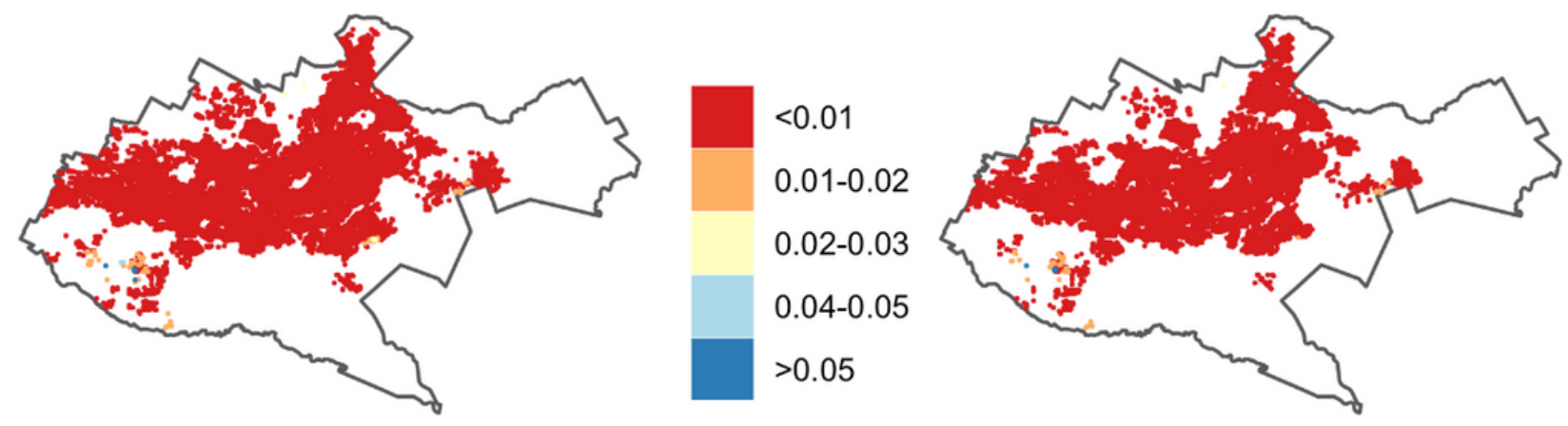

$<0.01$

0.01-0.02

$0.02-0.03$

$\leq 45$ minutes (Peak time)

$\leq 45$ minutes (Off peak time)
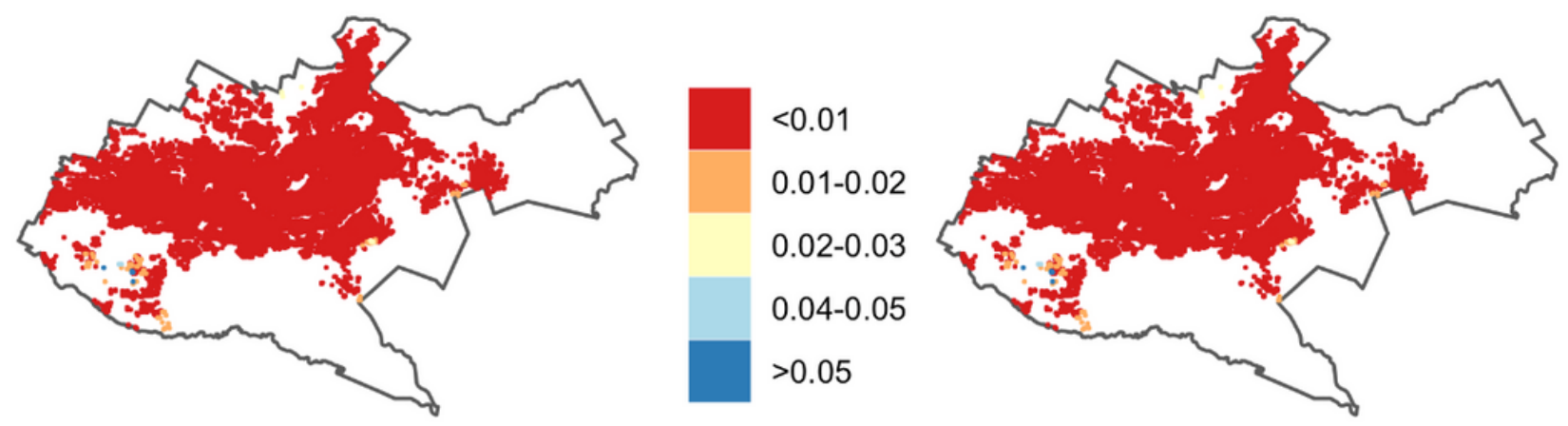

$<0.01$

0.01-0.02

0.02-0.03

0.04-0.05

$>0.05$

\section{Figure 3}

Accessibility index (population: facility ratios) for primary health care in Nairobi within 15-, 30- and 45minutes' drive during peak and off-peak traffic times. The white areas have no accessibility to health facilities. Shapefile source: GADM 


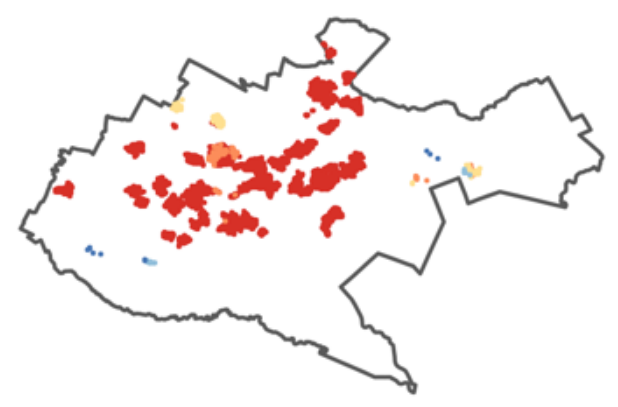

$\leq 30$ minutes (Peak time)

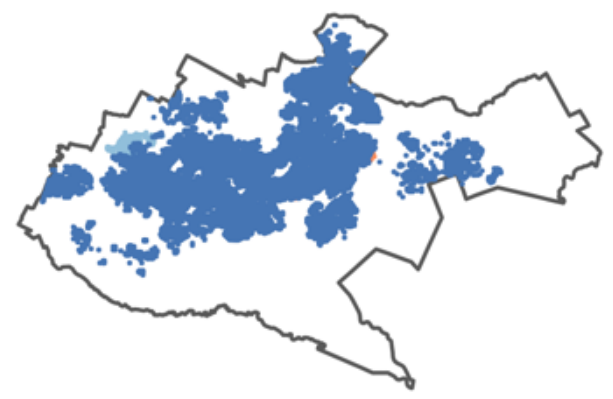

$\leq 45$ minutes (Peak time)

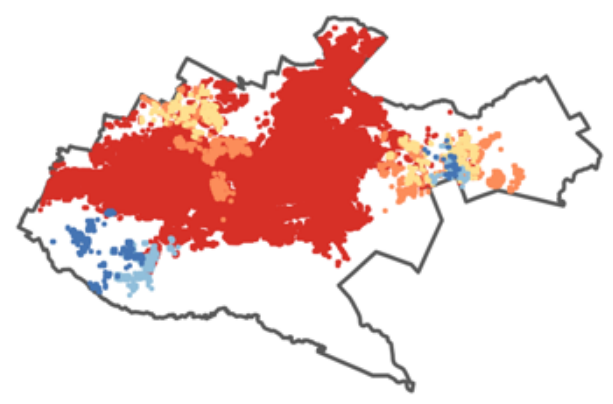

$<0.0001$

0.0001-0.0002

0.0002-0.0003

0.0004-0.0005

$>0.0005$

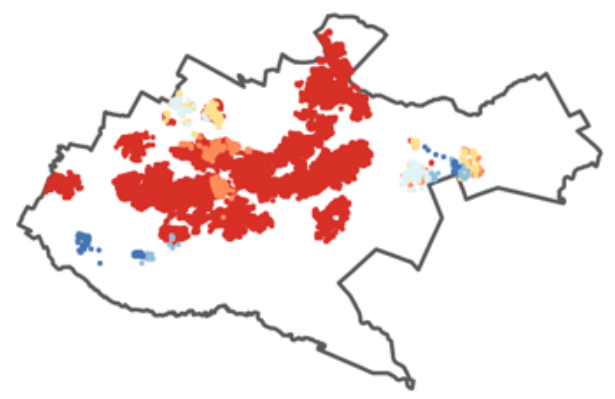

$\leq 30$ minutes (Off-peak time)

0.0001-0.0002 0.0004-0.0005 $>0.0005$

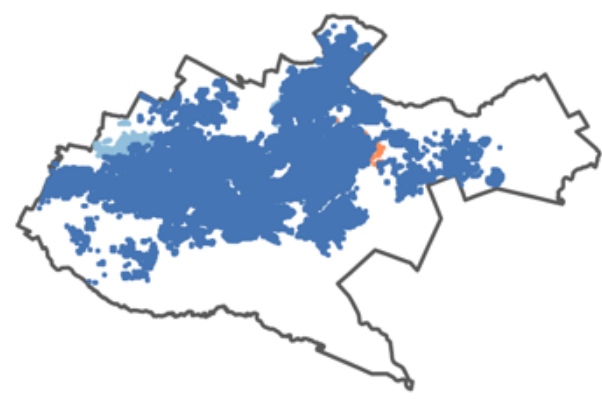

0.0001-0.0002 0.0004-0.0005 $>0.0005$

$\leq 45$ minutes (Off-peak time)
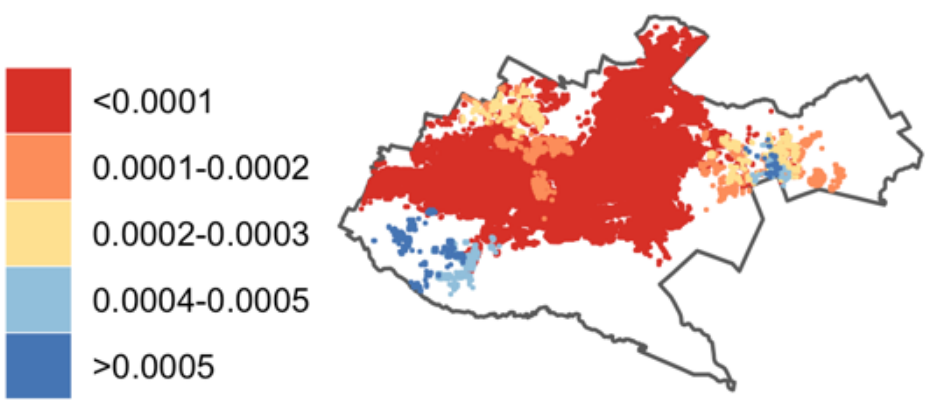

$<0.0001$

0.0001-0.0002

$0.0002-0.0003$

$0.0004-0.0005$

$>0.0005$

\section{Figure 4}

Accessibility index (population: facility ratios) for secondary healthcare in Nairobi within 15-, 30- and 45minutes' drive during peak and off-peak traffic times. The white areas have no accessibility to health facilities. Shapefile source: GADM(26). 
$\leq 15$ minutes (Peak time)

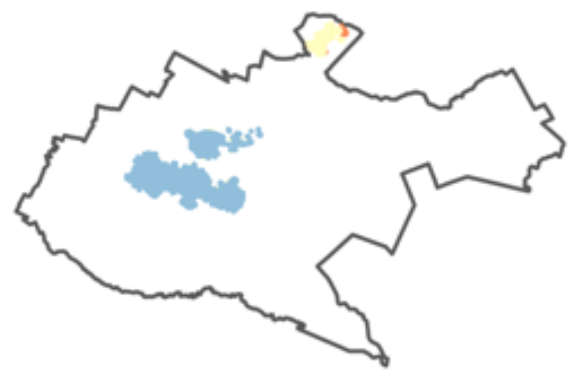

$\leq 30$ minutes (Peak time)

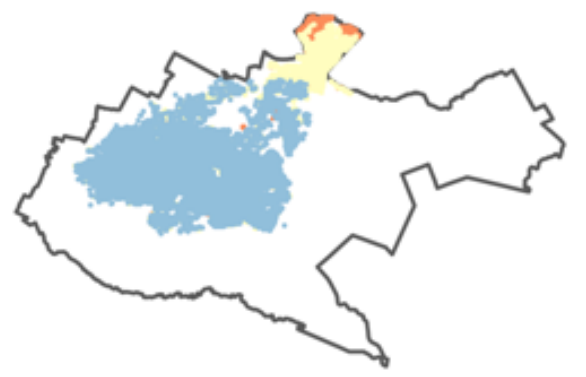

$\leq 45$ minutes (Peak time)

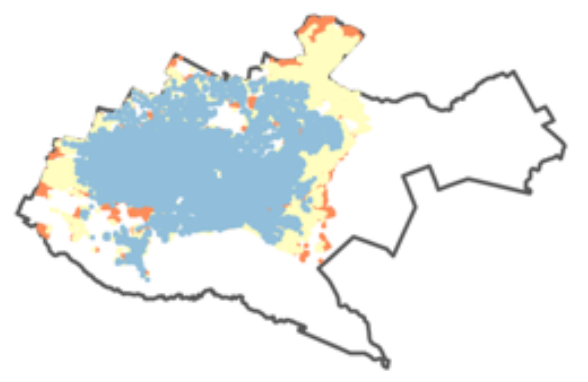

$<0.00001$

0.00001-0.00002
$0.00002-0.00003$

$\leq 15$ minutes (Off-peak time)

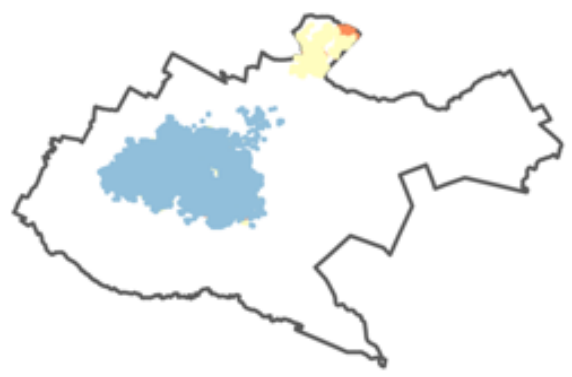

$\leq 30$ minutes (Off-peak time)

$<0.00001$

0.00001-0.00002

0.00002-0.00003

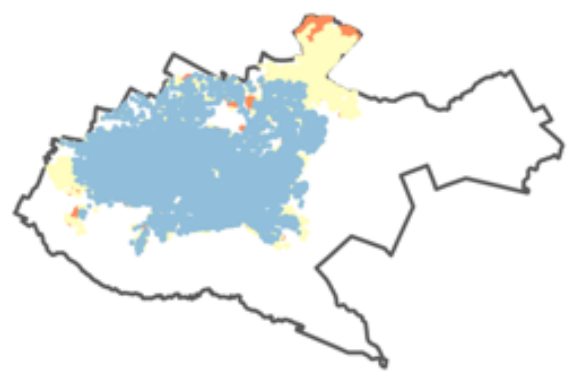

$<0.00001$
$0.00001-0.00002$
$0.00002-0.00003$

$\leq 45$ minutes (Off-peak time)

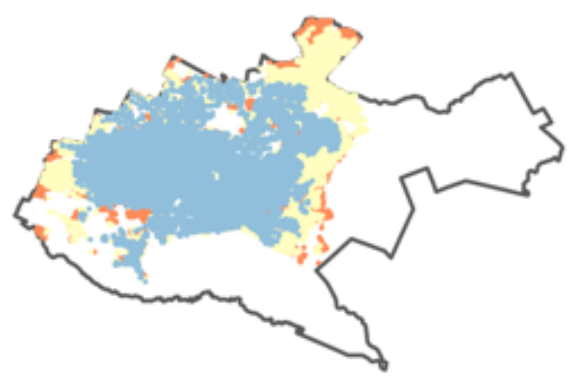

$<0.00001$

0.00001-0.00002
$0.00002-0.00003$

\section{Figure 5}

Accessibility index (population: facility ratios) for tertiary health care in Nairobi within 15-, 30- and 45minutes' drive during peak and off-peak traffic times. The white areas have no accessibility to health facilities. Shapefile source: GADM 

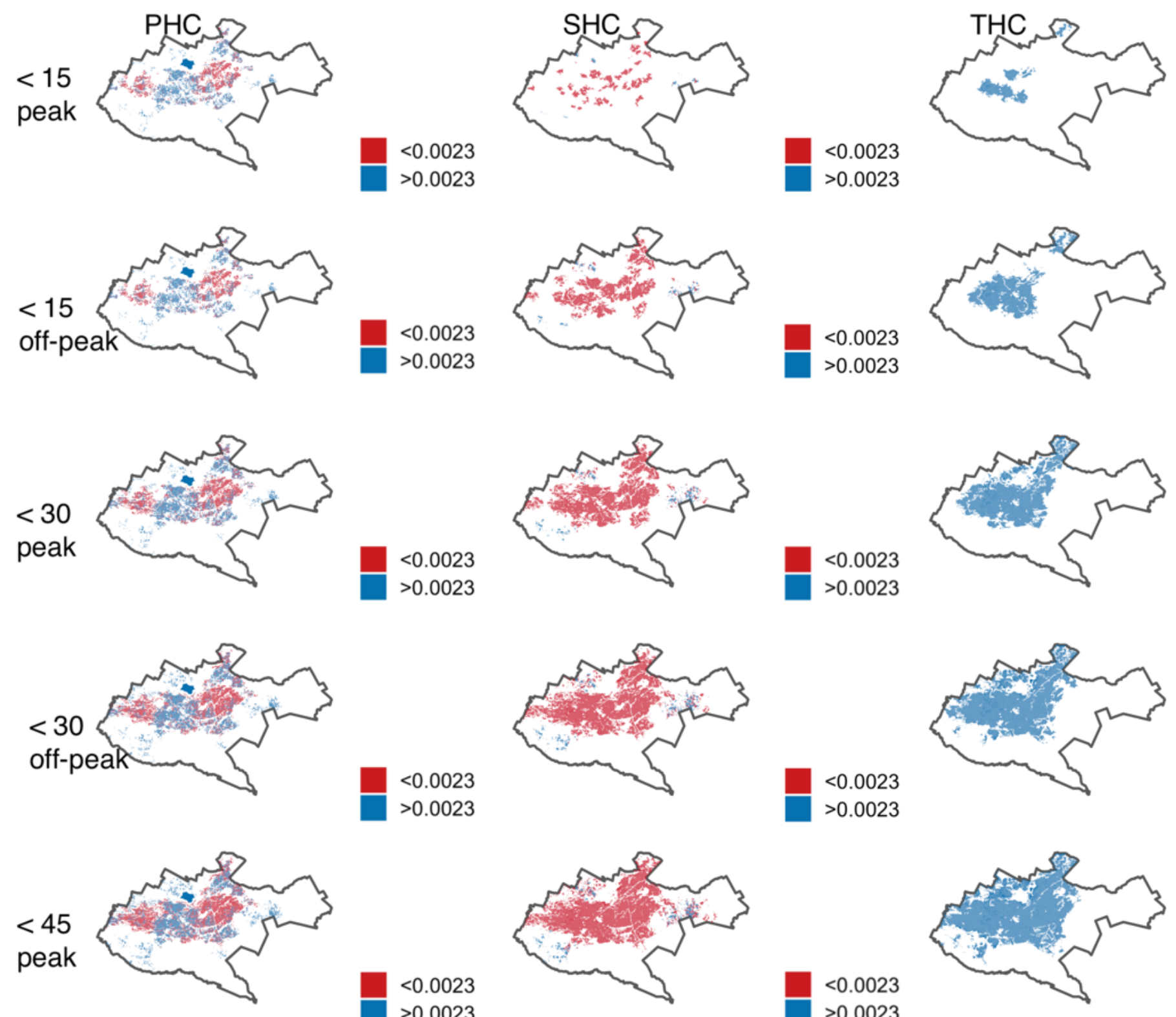

$<0.0023$
$>0.0023$

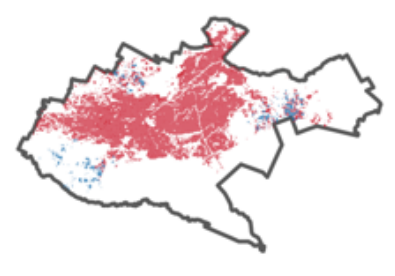

$>0.0023$
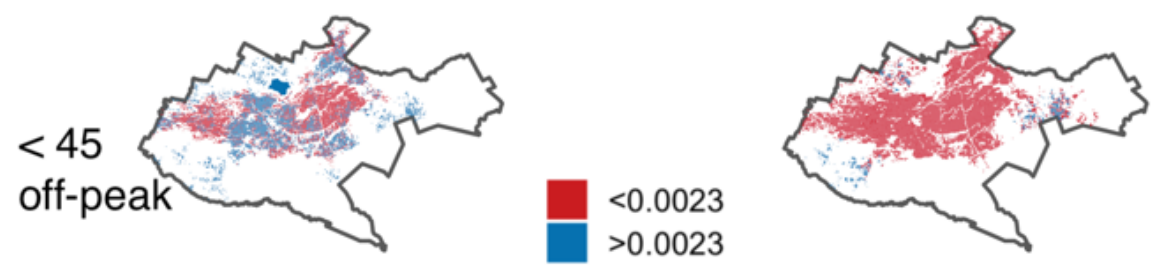

$<0.0023$

$>0.0023$
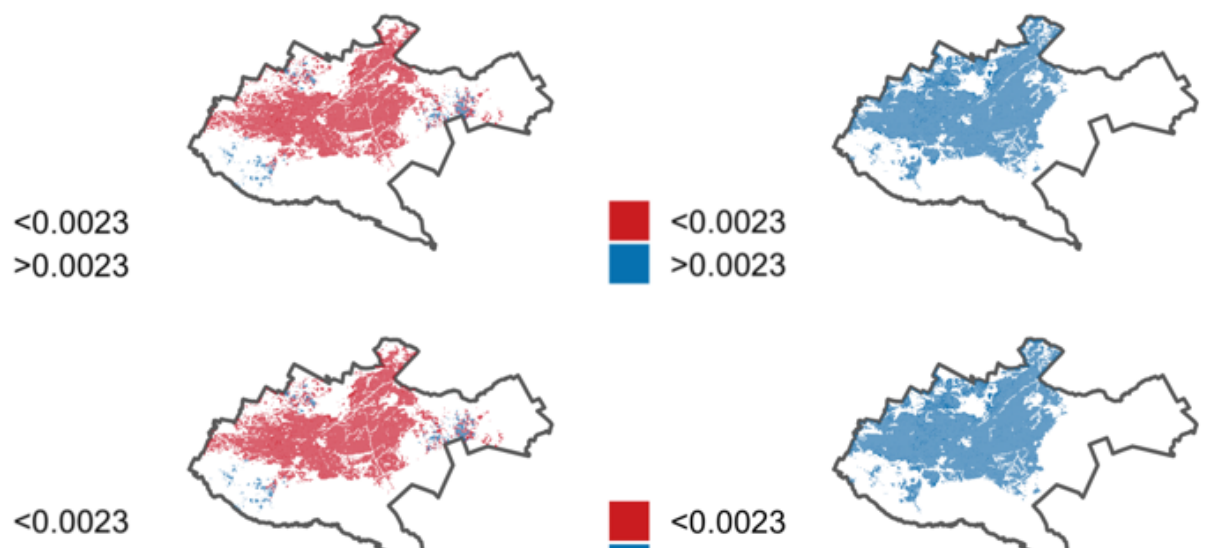

$>0.0023$

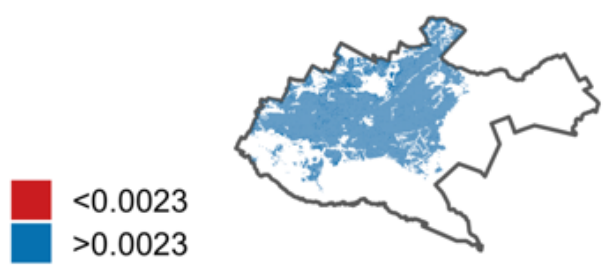

\section{Figure 6}

Accessibility index (population: health care professional ratios) by facility tier for primary (PHC), secondary (SHC) and tertiary (THC) health care in Nairobi within 15-, 30- and 45-minutes' drive during peak and off-peak traffic times. The white areas have no accessibility to health care professionals. Shapefile source: GADM 